\title{
Deposition of Zinc Oxide and Layered Basic Zinc Salts from Aqueous Solutions Containing Amino Acids and Dipeptides
}

\author{
Peter GERSTEL, Peter LIPOWSKY, Olivier DURUPTHY, Rudolf C. HOFFMANN, Paul BELLINA, \\ Joachim BILL and Fritz ALDINGER
}

Max-Planck-Institut fur Metallforschung and Institut fur Nichtmetallische Anorganische Materialien, Universitat Stuttgart, Pulvermetallurgisches Laboratorium, Heisenbergstr. 3, D-70569 Stuttgart, Germany

\begin{abstract}
Deposition experiments from aqueous solutions of zinc nitrate were performed in a bio-inspired way using biomolecules as directing agents. A global overview of the effect of various amino acids (8) and dipeptides (21) was done in term of structure and morphology of the obtained coating. The selection of certain biomolecules leads to the formation of smooth $\mathrm{ZnO}$ thin films. Variations of the amino acid chemical function and the sequence used within the peptides combination give rise to a wide variety of morphologies ranging from films to three dimensional nets. The data obtained from scanning electron microscopy and X-ray diffraction are discussed and correlated to the chemical properties of the biomolecules.
\end{abstract}

[Received July 10, 2006; Accepted August 24, 2006]

Key-words : Bio-inspired synthesis, Films, Chemical bath deposition, Zinc oxide, Amino acid, Peptide, Layered basic zinc salt

1. Introduction

Numerous publications deal with the influence of organic additives on the formation, growth and morphology of particles $^{1)}$ and coatings ${ }^{2,3)}$ in various types of precipitation reactions ${ }^{4)}$ from aqueous solutions. Apart from the technical significance, ${ }^{5)}$ such investigations are relevant for the understanding of biomineralization processes. ${ }^{6}$ Important recent contributions to the understanding and mimicking of these processes can be found in the literature. ${ }^{7)-11)}$ However, the influence of biomolecules of high molecular weight such as peptides and sugars is still not completely understood. ${ }^{6,12)}$ It now becomes evident, that specific binding sites must exist for the interaction of the biomolecules and the involved inorganic species (metal ions first, ceramic surfaces later) during the mineralization, which are responsible for the final shape and structure of the biomineral. ${ }^{13)-15)}$ The identification of such binding sites can be achieved through the modification of known control proteins. ${ }^{16)}$ For a complete understanding, though, it is also helpful to investigate the behaviour of simple amino acids and dipeptides in mineralization. ${ }^{17), 18)}$

In the course of the research for the generation of thin film coatings by Chemical Bath Deposition $(\mathrm{CBD})^{17), 19), 20)}$ the thermohydrolysis of solutions of zinc nitrate in the presence of amino acids and dipeptides has been investigated. Although the composition of the reaction solutions differed only in the added bioorganic component, the obtained coatings exhibited an astonishingly broad bandwidth with respect to chemical composition as well as morphology and microstructure. ${ }^{17)}$

The present manuscript attempts a systematic investigation to reveal the specific influence of this class of organic additives in mineralization reactions. Therefore a great variety of amino acids and dipeptides was tested. Furthermore, to exclude a possible substrate influence, various substrates were also employed. Accordingly depositions were carried out on silicon as well as on polyelectrolyte multilayers. Finally, thermal treatment was performed on selected samples to modify the final structure of the coatings.

\section{Experimental}

2.1 Substrate preparation

Substrates consisted of surface oxidized silicon, whereby further modification with layer-by-layer assemblies (Lbls) of polyelectrolytes was also employed. Deposition experiments were carried out on both types of surfaces.

Silicon wafers were cleaned and surface oxidized in Piranha solution [conc. $\mathrm{H}_{2} \mathrm{SO}_{4}: \mathrm{H}_{2} \mathrm{O}_{2} \quad(30 \mathrm{wt} \%$ in water $)=70: 30$ vol.], washed abundantly with distilled water and dried in an argon stream prior to use. Lbls of polyelectrolytes were prepared, if applied in the deposition experiment, by dipping the silicon wafer in an aqueous $0.5 \mathrm{wt} \%$ solution of the desired polyelectrolyte for 20 minutes, followed by immersion in distilled water for 5 minutes. Subsequent layers were obtained without intermediate drying between the immersions in oppositely charged polyelectrolytes according to published procedures. $^{21)}$ Aqueous polyelectrolyte solutions were obtained from commercially available products by dilution with water (Polyethyleneimine-PEI (Aldrich, $M_{\mathrm{W}} 70,000$ ); Poly (sodium 4-styrenesulfonate)-PSS (Aldrich, $M_{\mathrm{W}}$ 70,000) and Poly (allylamine hydrochloride)-PAH (Aldrich, $M_{\mathrm{W}}$ 70,000)). The $\mathrm{pH}$ of the PEI solution was adjusted to 3 with hydrochloric acid, PS and PAH solutions were used without further conditioning. All Lbls in this work had the sequence (PEI/PSS) $(\mathrm{PAH} / \mathrm{PSS})_{7}$.

\subsection{Deposition experiments}

Several series of deposition experiments were carried out with zinc nitrate and hexamethylenetetramine (HMTA) concentrations in the reaction solution of either 15 or $30 \mathrm{mM}$, with a constant ratio of $[\mathrm{Zn}]:[$ HMTA $]$ of $1: 1$ but varying ratios of amino acids or dipeptides $[\mathrm{Zn}]:[\mathrm{bio}]$ ranging from $1: 1$ to $8: 1$. The stereo configuration of all amino acids including those in dipeptides was L. To ensure optically clear starting solutions all compounds were mixed always freshly prior to use. Therefore amino acids or peptides were dissolved in an HMTA stock solution and mixed with according volumes of a zinc nitrate solution to obtain the above-mentioned concentrations.

Substrates were immersed in $2 \mathrm{~mL}$ aliquots of the reaction solution at $333 \mathrm{~K}$ until the onset of visible turbidity in the case of His and Gly-His. Longer reaction times did not lead to significantly thicker films and larger agglomerates from the solution sedimented on the substrate. In the case of $[\mathrm{Zn}]=15 \mathrm{mM}$ turbidity was observed after $4.5 \mathrm{~h}$ for $[\mathrm{Zn}]:[\mathrm{His}]=1: 1,5.5 \mathrm{~h}$ 


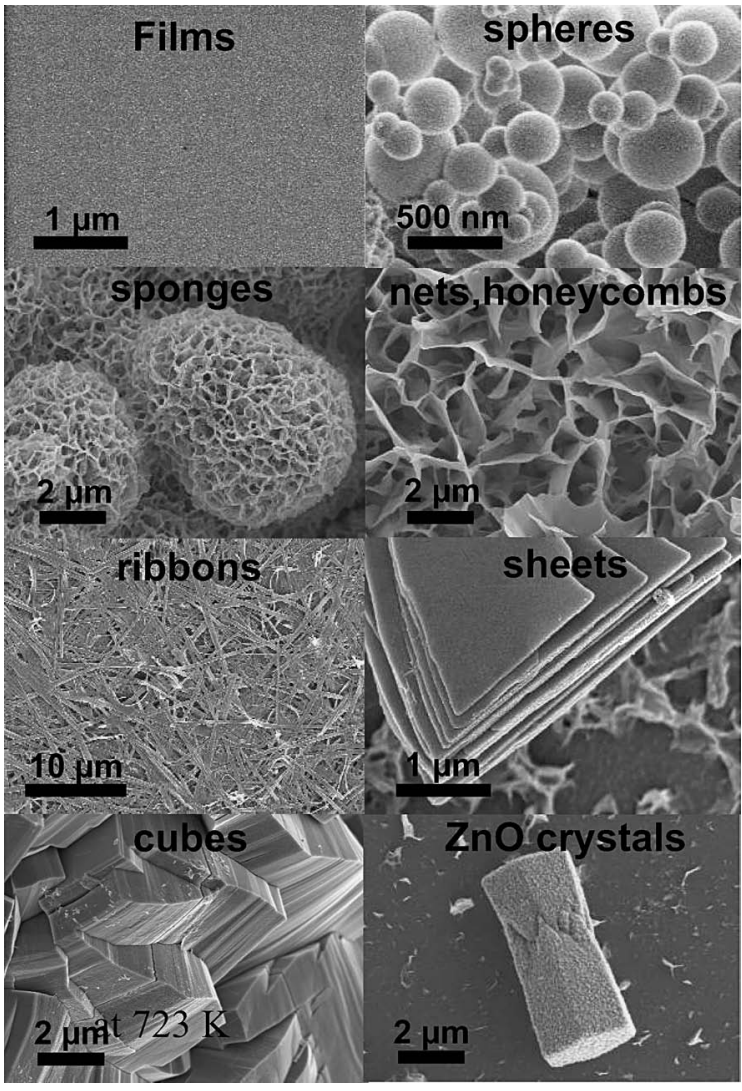

Fig. 1. Typical morphologies of deposits obtained from the thermohydrolysis of zinc nitrate with HMTA in the presence of amino acids or dipeptides.

for $[\mathrm{Zn}]:[\mathrm{His}]=2: 1,6.5$ for $[\mathrm{Zn}]:[\mathrm{His}]=4: 1$ and $3.5 \mathrm{~h}$ for $[\mathrm{Zn}]:[\mathrm{Gly}-\mathrm{His}]=2: 1$, respectively. In the case of $[\mathrm{Zn}]$ : $[\mathrm{His}]=8: 1$ no turbidity was observed till the termination of the reaction after $6.75 \mathrm{~h}$. Depositions with all other amino acids or peptides were carried out for 48 hours at $333 \mathrm{~K}$.

2.3 Film characterization

Micrographs were taken with a Zeiss DSM 982 Gemini at $1.7 \mathrm{kV}$ or a Jeol $6300 \mathrm{~F}$ at $2 \mathrm{kV}$. X-ray diffraction (XRD): Diagrams were measured with a Siemens D5000 Kristalloflex or a Philips MRD diffractometer, respectively, which were both operated in Bragg-Brentano geometry using $\mathrm{Cu} \mathrm{K}_{\alpha 1}$ radition. Transmission electron microscopy (TEM) characterization was conducted with a JEOL JEM 4000 EX operated at $400 \mathrm{kV}$. The cross-section specimen for the TEM investigation has been prepared according to conventional techniques described elsewhere. ${ }^{22)}$

\subsection{Determination of isoelectric points}

$1 \mathrm{mmol}$ of the dipeptide were dissolved in $20.0 \mathrm{~mL}$ of a $0.200 \mathrm{M}$ hydrochloric acid solution. Titrations were carried out using $0.500 \mathrm{M} \mathrm{NaOH}$ (Fixanal) and a Metrohm Titrando 836 unit. The $\mathrm{pH}$ value was determined after addition of 0.01 $\mathrm{mL}$ of titrant at a time. Isoelectric points (IEP) were deduced from the automatically calculated $\mathrm{pKa}$ values, which were determined from the minima in the first derivative of the titration curves.

\section{Results and discussion}

The addition of amino acids or peptides to the reaction solution had a significant influence on the microstructure of the deposition products as shown in Fig. 1. The exhibited mor-

\begin{tabular}{|c|c|c|c|c|c|c|c|c|}
\hline $\mathrm{Zn} / \mathrm{pep}$ & \multicolumn{2}{|c|}{$1 / 1$} & \multicolumn{2}{|c|}{$2 / 1$} & \multicolumn{2}{|c|}{$4 / 1$} & \multicolumn{2}{|c|}{$8 / 1$} \\
\hline$[\mathrm{Zn}] \mathrm{mM}$ & 15 & 30 & 15 & 30 & 15 & 30 & 15 & 30 \\
\hline Gly & & & & & & & 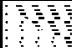 & \\
\hline Gly-Gly & & & & 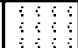 & $\equiv$ & & & \\
\hline Pro & & & & & & & & \\
\hline Pro-Gly & & & $:$ & $\vdots$ & & $=$ & & \\
\hline Gly-Pro & & & & & & & & \\
\hline Pro-Pro & & & & & & & & \\
\hline Asp & & & & & & 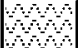 & & \\
\hline Asp-Gly & & & & & 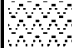 & n & & \\
\hline Gly-Asp & & & & & & 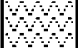 & & \\
\hline Asp-Asp & & & & & 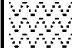 & 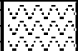 & & \\
\hline Glu & & & & & & & & \\
\hline Glu-Gly & & & & & 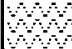 & & & \\
\hline Gly-Glu & & & & & & & & \\
\hline Glu-Glu & & & & & 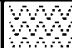 & 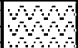 & n & \\
\hline Cys & & & & & & & & \\
\hline Cys-Gly & es & n' & এ & Pes & נe & Pu & m & \\
\hline Gly-Cys & 点高 & 墔高 & 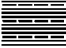 & 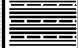 & 高高 & 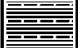 & 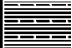 & 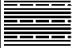 \\
\hline His & 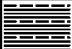 & 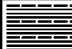 & 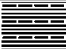 & 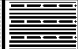 & 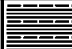 & 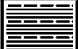 & 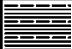 & 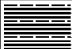 \\
\hline His-Gly & 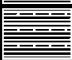 & 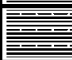 & 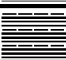 & 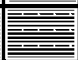 & 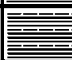 & 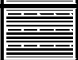 & 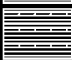 & 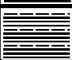 \\
\hline Gly-His & 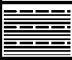 & 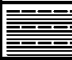 & 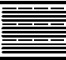 & 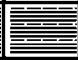 & 高高 & 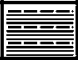 & & 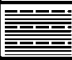 \\
\hline His-His & 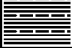 & 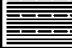 & 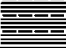 & 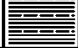 & 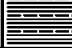 & 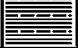 & 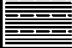 & 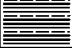 \\
\hline $\operatorname{Trp}$ & 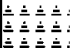 & 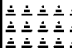 & 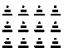 & 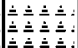 & 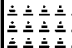 & 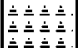 & 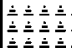 & 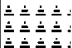 \\
\hline Trp-Gly & & & & & & & & \\
\hline Gly-Trp & 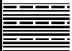 & 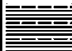 & 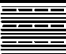 & 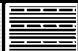 & 4 & & & \\
\hline Trp-Trp & 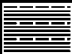 & 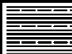 & 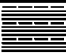 & 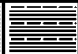 & 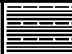 & 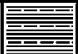 & 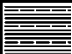 & 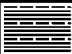 \\
\hline Arg & 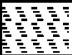 & 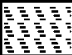 & 年 & 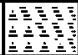 & 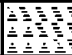 & 年 & 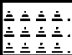 & 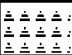 \\
\hline Arg-Gly & $\therefore$ & 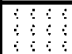 & 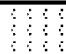 & 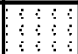 & 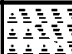 & \begin{tabular}{|l|l} 
\\
\hdashline
\end{tabular} & 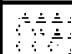 & \\
\hline Gly-Arg & $\because$ & 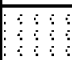 & 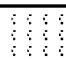 & 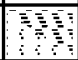 & $\because \because$ & 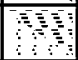 & 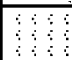 & \\
\hline Arg-Arg & & & & & & $\because 1$ & 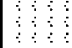 & \\
\hline
\end{tabular}

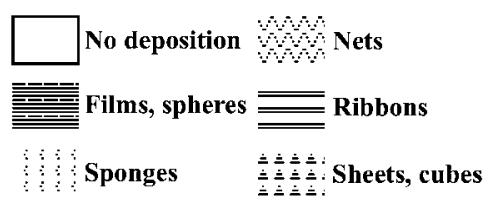

Fig. 2. Overview of obtained morphologies in dependence of the composition of the reaction solution, i.e. concentration and ratio of zinc salt: organic additive as well as type of added amino acid or dipeptide.

phologies included films displaying interference colours as well as sponge-, honeycomb- or ribbon-shaped coatings. Other deposits appeared as spheres, sheets or cubes. Moreover the typical shape of hexagonal zinc oxide crystals was also found. A detailed summary about all experiments and the observed morphologies in dependence on the composition of the reaction solution can be found in Fig. 2 . 
Table 1. Structure and Products Obtained with Selected Amino Acids and Dipeptides

\begin{tabular}{|c|c|c|c|c|}
\hline Additive & Structure formula & IEP & $\begin{array}{c}\text { Morphology } \\
\text { of deposit }\end{array}$ & $\begin{array}{l}\text { Deposition } \\
\text { product }^{*}\end{array}$ \\
\hline Gly & & 6.0 & $\begin{array}{l}\text { Micrometric } \\
\text { crystals }\end{array}$ & Zinc oxide \\
\hline Gly-Gly & & $5.6^{*}$ & $\begin{array}{c}\text { Micrometric } \\
\text { erystals }\end{array}$ & 7inc oxide \\
\hline Glu & & 3.2 & $\begin{array}{l}\text { Ribbon-like } \\
\text { coating }\end{array}$ & LBZ \\
\hline Gly-Glu & & $3.7^{*}$ & $\begin{array}{l}\text { Ribbon-like } \\
\text { coating }\end{array}$ & LBZ \\
\hline Glu-Gly & & $3.6^{*}$ & $\begin{array}{l}\text { Net-like } \\
\text { coating }\end{array}$ & LBZ \\
\hline Glu-Glu & & n.d. ${ }^{*}$ & $\begin{array}{l}\text { Net-like } \\
\text { coating }\end{array}$ & LBZ \\
\hline
\end{tabular}

Since it is challenging to assess and classify such plethora of data, the influence of the amino acids Gly and Glu as well as all dipeptides derived from combinations of these two (Gly-Gly, Glu-Glu, Glu-Gly and Gly-Glu) will be discussed here as an instructive example in more detail. Data corresponding to those additives such as structural formula, IEP, morphology and structure of deposit are listed in Table 1. Various concentrations and ratios of $[\mathrm{Zn}]$ to amino acid/ dipeptide were investigated as well as the type of substrate (silicon without or with modification by polyelectrolyte multilayers). The resulting morphologies of the deposits are shown in Fig. 3 and Fig. 4, respectively. The use of Gly or corresponding dipeptide Gly-Gly as additives in the reaction solution leads to the growth of hexagonal crystals in addition to sponge-like deposits for low additives amounts. No complete surface coverage of the substrates was observed, though. The employment of Glu and Glu-Glu resulted in the growth of different morphologies. The addition of Glu yielded ribbonlike coatings, whereas the one of Glu-Glu yielded net-like shapes corresponding to an important twisting of the ribbons. Interestingly Gly-Glu and Gly-Glu lead to rather different morphologies. Whereas Gly-Glu yielded ribbon-like coatings, net-shaped deposits were obtained using Glu-Gly. Owing to SEM investigations, the amount of the deposited coatings with Glu and Glu-containing dipeptides was significantly larger compared to the use of Gly or Gly-Gly. It has to be noted here that in the presence of high amounts of any of the additives, no deposition was observed after $48 \mathrm{~h}$.



Fig. 3. SEM micrographs of deposits on silicon obtained from solutions of $30 \mathrm{mM}[\mathrm{Zn}], 30 \mathrm{mM}$ HMTA and $3.75 \mathrm{mM}$ additive (Gly, Gly-Gly, Gly-Glu, Glu, Glu-Glu or Glu-Gly).

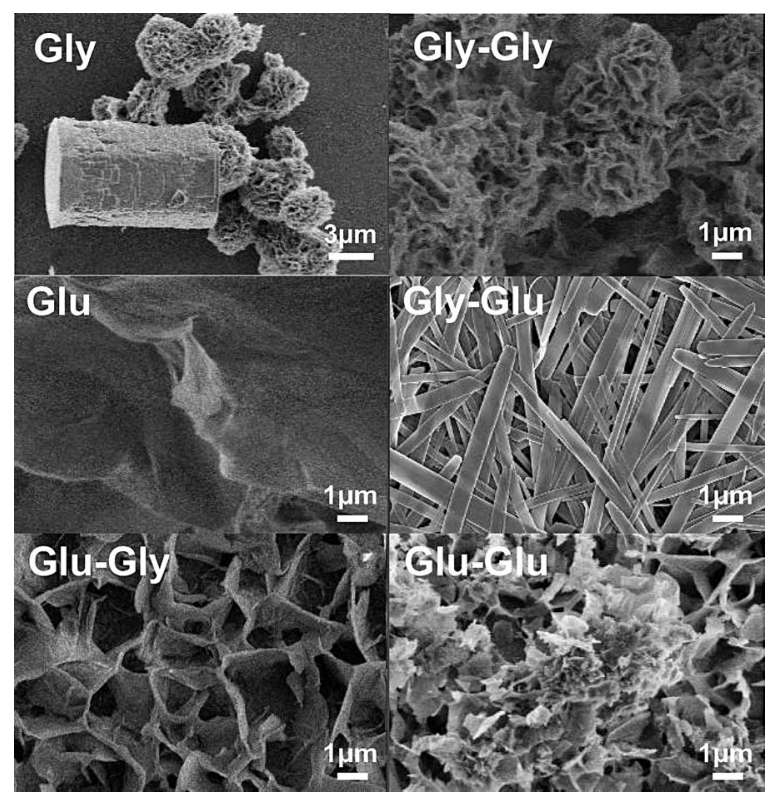

Fig. 4. SEM micrographs of deposits on polyelectrolyte multilayers obtained from solutions of $30 \mathrm{mM}[\mathrm{Zn}], 30 \mathrm{mM}$ HMTA and 3.75 $\mathrm{mM}$ additive (Gly, Gly-Gly, Gly-Glu, Glu, Glu-Glu or Glu-Gly) after $48 \mathrm{~h}$ at $333 \mathrm{~K}$.

The morphology of deposits on polyelectrolyte multilayers (Fig. 4) did not differ significantly from those obtained on unmodified silicon (Fig. 3). The SEM micrographs suggest, however, a more homogeneous surface coverage and a stronger film growth (see e.g. Figs. 3 and 4, Gly-Gly).

For analysis of the chemical composition the deposits were investigated by means of XRD (Fig. 5 and Fig. 6). In case of deposition reactions employing Gly or Gly-Gly only signals of $\mathrm{ZnO}$ could be identified in the product. The rather poor signal to noise ratio observed confirms the week material deposition 


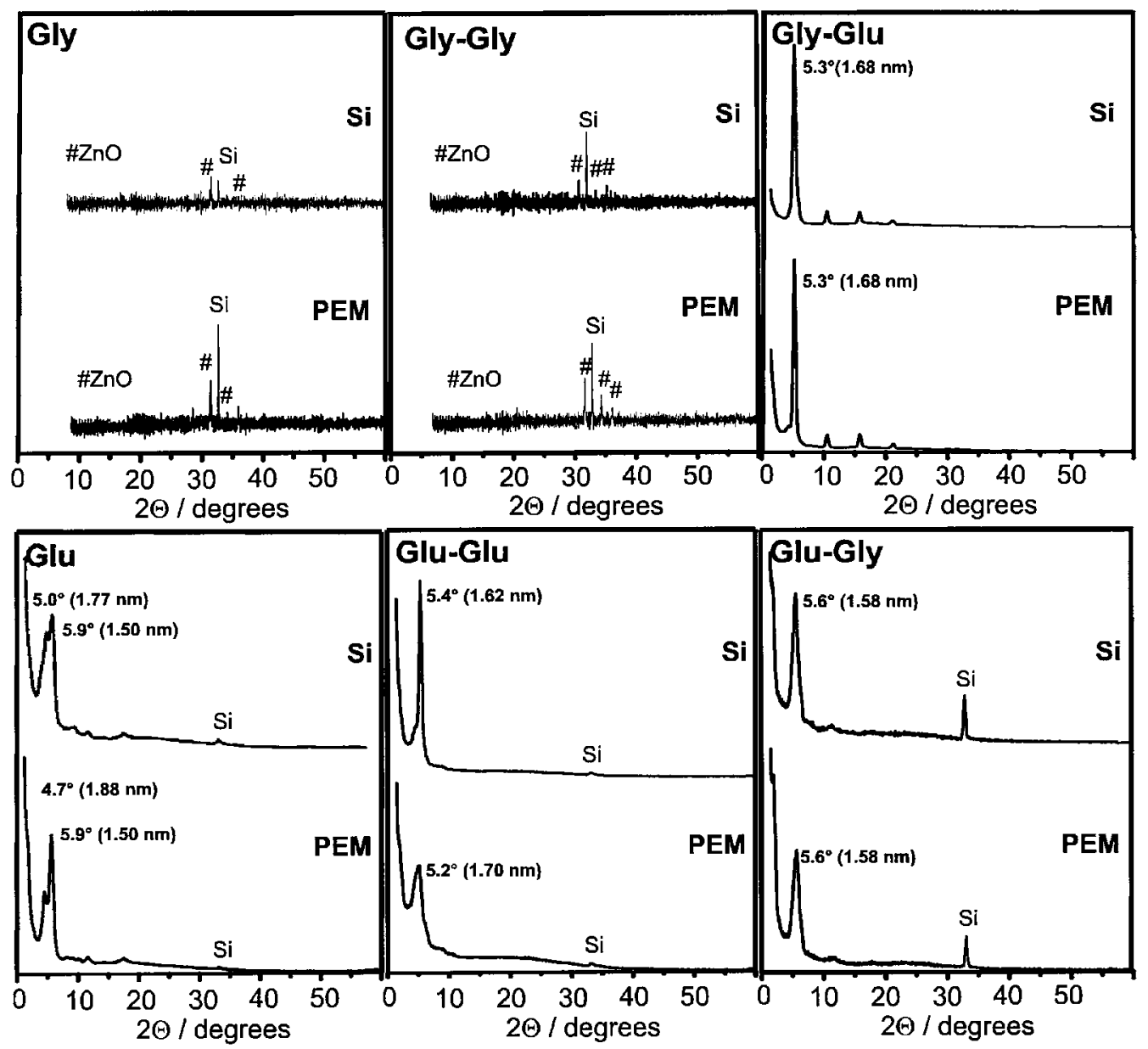

Fig. 5. XRD diagrams of deposits on silicon as well as polyelectrolyte multilayers, obtained from solutions of $30 \mathrm{mM}$ [Zn], $30 \mathrm{mM} \mathrm{HMTA}$ and $3.75 \mathrm{mM}$ of various amino acids/dipeptides (Gly, Gly-Gly, Gly-Glu, Glu, Glu-Glu or Glu-Gly) after $48 \mathrm{~h}$ at $333 \mathrm{~K}$.

in the presence of those additives. For Glu and Glu containing dipeptides, however, the X-ray patterns suggested the presence of layered basic zinc salts (LBZs).

LBZs possess a specific layered structure, that is best described in terms of $\left[\left(\mathrm{Zn}^{\text {octa }}\right)_{3}\left(\mathrm{Zn}^{\text {tetra }}\right)_{2}(\mathrm{OH})_{8}\right]^{2+} \cdot 2\left(\mathrm{~A}^{-}\right)$ - $n \mathrm{H}_{2} \mathrm{O}$ and consists of infinite brucite layers, where one quarter of the zinc atoms in the octahedral interstices are omitted. On both sides of the empty octahedra $\mathrm{Zn}$ atoms are located that are tetrahedrally coordinated. The tetrahedral zinc sites are coordinated by three $\mathrm{OH}^{-}$ions of the brucite layers. The fourth apex of these coordination tetrahedra point into the interlayer space and can then be occupied either by the anion $\left(\right.$ for $\mathrm{Cl}^{-}$) or by a water molecule whereby the anion is freely situated in the interlayer (in the case of $\mathrm{NO}_{3}{ }^{-}$). ${ }^{23)-25 \text { ) }}$

Whereas the before-mentioned LBZs comprise ordered stacking of the brucite layers, the intercalation of carboxylate anions leads to turbostratic disorder as in the case of basic zinc acetate. ${ }^{26), 27)}$ The resulting diffraction pattern consists of sharp reflections in the range of small diffraction angles and broad asymmetric peaks at high angles. ${ }^{26)}$ These reflections correspond to the $(001)$ and $(h k 0)$ peaks, respectively, as all of the mixed $(h k \mathrm{l})$ peaks are suppressed completely by the randomness in translation and rotation. ${ }^{28)}$

The reflection patterns depend on the composition of the reaction solution and the surface modification of the substrate (Figs. 5 and 6). Although the deposits on silicon compared to those on polyelectrolyte multilayers exhibit the same reflec- tions, there are significant differences in the relative intensity. It was suggested, that this effect is due to texture which might arise from growth induced by heterogeneous nucleation. ${ }^{17)}$

As mentioned above the first reflection is attributed to the (001) peak and therefore related to the basal spacing, i.e. interlayer distance of the brucite layers in the LBZs.

Numerous articles deal with the intercalation of amino acids in layered double hydroxide $\left(\mathrm{LDH},\left[\mathrm{M}_{1-x}^{2+} \mathrm{M}_{x}^{3+}(\mathrm{OH})_{2}\right]\right.$ $\left[A_{x}{ }^{n-} / n . y \mathrm{H}_{2} \mathrm{O}\right], M_{1}=\mathrm{Mg}, \mathrm{Zn}, \mathrm{Cu}$ and $\left.M_{2}=\mathrm{Al}, \mathrm{Fe}\right)$ materials and the interlayer distance was correlated both to the size of the intercalated species and their orientation between the inorganic planes. ${ }^{29)-34)}$ As an example, depending on the nature of the LDH composition and the synthesis process of the LDH-Glu hybrid, the interlayer space was expanded from 0.3 to $0.8 \mathrm{~nm}$ with the amino acid intercalation. ${ }^{29), 31), 33)}$ Depending on the experimental conditions, the measured interlayer distances in the LBZs with Glu, Gly-Glu, Glu-Gly and Glu-Glu are $1.5-1.6 \mathrm{~nm}, 1.7 \mathrm{~nm}, 1.5-1.7 \mathrm{~nm}$ and $1.6-1.9 \mathrm{~nm}$, respectively. These values can be compared to the $1.3-1.5 \mathrm{~nm}$ interlayer distance measured in basic zinc acetate. ${ }^{35)}$ The interlayer space increases with the size of the additive in agreement with a vertical orientation of the biomolecules also found in other systems. ${ }^{18), 29), 33)}$ However the water molecules present between the layer in addition to the intercalated species may also have an important influence on the interlayer distance. ${ }^{35)}$

In some cases two proximate basal spacings or a pronounced shoulder of the first reflection were visible in 

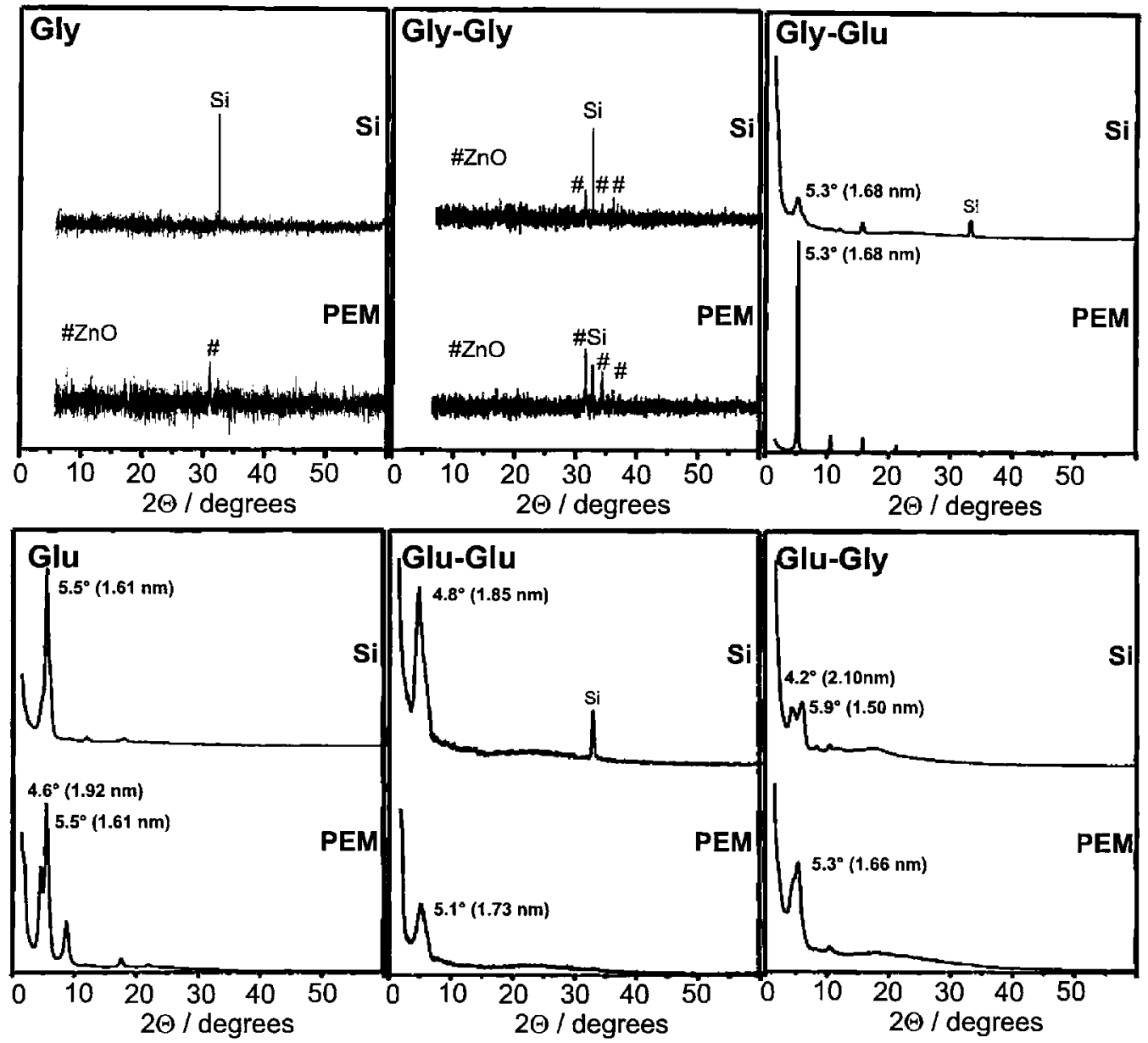

Fig. 6. XRD diagrams of deposits on silicon as well as polyelectrolyte multilayers, obtained from solutions of $15 \mathrm{mM}$ [Zn], $15 \mathrm{mM} \mathrm{HMTA}$ and $1.88 \mathrm{mM}$ of various amino acids/dipeptides (Gly, Gly-Gly, Gly-Glu, Glu, Glu-Glu or Glu-Gly) after $48 \mathrm{~h}$ at $333 \mathrm{~K}$.

the XRD diagrams. These findings might, however, not indicate the presence of several phases, ${ }^{36)}$ but could also be related to a different number or orientation of the biomolecules in the interlayer space. ${ }^{29)}$,32) A drying effects can also explained such results as different water amounts can be observed in the interlayers. $^{30)}$

In any case the layer structures of the LBZs exhibit a great structural flexibility, which determine the superior ion exchange properties of this class of materials. ${ }^{37)}$ For a further interpretation an analysis of the composition would be necessary to reveal the amount of the different types of anions, which might be incorporated, such as organic anions, hydroxide or nitrate. ${ }^{29)}$

How can the influence of the organic molecules on the inorganic condensation be understood? The $\mathrm{pH}$-value of the reaction solutions was between 5.9 and 7.1 in all cases, whereby the $\mathrm{pH}$ increased slightly during the course of the reaction. Amino acids and peptides may modify the condensation mechanism through the formation of $\mathrm{Zn}$ (II) complexes in solution or through the preferential stabilization of certain solid phase. Amino acids as free molecules or incorporated in a protein that are more likely to form complexes with $\mathrm{Zn}$ (II) are His, Cys and Glu. ${ }^{38)-41)}$ On the contrary, Gly and Pro amino acids as well as the corresponding dipeptides do not display any complexing function on their side chains. Moreover, the IEPs of those species are close to 6 and consequently exist in the form of zwitterions in the reacting solution. The influence on the mineralization is therefore quite weak. This is indicated by the presence of micrometric zinc oxide particles on the substrate similar to those observed in the absence of additive. In contrast Glu, Asp and the corresponding dipeptides possess a second carboxyl function in the side chain. The formation of $\mathrm{Zn}(\mathrm{II})$ complexes in solution at low $[\mathrm{Zn}]$ :[additive $]$ ratio may explain the absence of any inorganic material deposition. At higher ratio, net- or ribbon-like morphologies consisting of LBZs are obtained. Thanks to the second carboxyl function, the IEP of these biomolecules is shifted to significantly lower $\mathrm{pH}$ values than the one employed in the reaction solutions. Therefore, they are present in a negatively charged form. Accordingly these additives interact strongly with zinc precursors in the course of the mineralization. This also supports the formation of basic zinc salts, in which the organic molecules are incorporated as anions. The formation of various morphologies might be due to different interactions of additive and zinc ions in the early stage of the condensation. Thus not all molecules possess two carboxyl functions in a conformation that is able to bind in a chelating mode. This may explain that the addition of Glu or Asp, only different on the side chain length, gave rise to significantly different morphologies. Similarly, the modification of the order of the amino acids in the Gly-Glu and Glu-Gly dipeptides increase the distance between the two carboxyl group and therefore may change its reactivity toward the metallic centre. The three amino acids His, Trp and Cys and the corresponding dipeptides are present in the 
reacting solution as zwitterions or as positively charged species. However, their possible interactions in solution with $\mathrm{Zn}$ (II) ions, respectively through the imidazole, the indole and the thiol group, prevent the formation of zinc oxide microcrystals. In His containing systems, smooth $\mathrm{ZnO}$ based films can be obtained in which strong assumptions of direct interactions between His and $\mathrm{Zn}(\mathrm{II})$ were shown. ${ }^{17)}$ In the presence of Trp or Cys and the dipeptides containing those amino acids, LBZs structures can be obtained in addition to such films. The significant modification of the interlayer distance observed previously ${ }^{17)}$ indicates an intercalation of the additives even if the positive charge of the inorganic layers is not balanced their presence.

The Arg amino acid and the corresponding dipeptides are positively charged around $\mathrm{pH}=7$ and the protonated guanidinium group of the side chain is not likely to coordinate to $\mathrm{Zn}(\mathrm{II})$ in those $\mathrm{pH}$ conditions. Consequently a relatively week effect is expected on the inorganic condensation and $\mathrm{ZnO}$ microcrystals are indeed obtained. However the LBZs structure can also be observed with sheet- and cube-like morphologies different from those observed previously. This can be understood in terms of LBZs crystals growth by a mineralization performed equally parallel and perpendicular to the layers. The measured interlayer distance of $0.96 \mathrm{~nm}$ with $\mathrm{Arg}^{17)}$ is close to the one of $\mathrm{Zn}_{5}(\mathrm{OH})_{8}\left(\mathrm{NO}_{3}\right)_{2} \cdot 2 \mathrm{H}_{2} \mathrm{O},{ }^{24)}$ therefore the absence of the positively charged biomolecule between the brucite layers is suggested. Such a statement may explain the new morphologies. Indeed, in the absence of big organic spacers between the inorganic layers (probably replaced by nitrate ions), a higher degree of order can be obtained due to a better defined interlayer space. Consequently a larger number of layers can be correctly stacked during the formation of the LBZs and less exfoliation may happen afterward. A similar loss of order in the direction perpendicular to the layers was already observed when comparing nitrate and acetate containing LBZSs. ${ }^{37}$ )

The different trends can be summarized as follows: the presence of additional acidic (in the case of Asp or Glu) or complexing (in the case of His or Trp and Cys) groups has a strong influence on the morphology of the deposits. In such cases layered basic zinc salts are most of the time formed, whereas in the absence of such side groups (as in the case of Pro or Gly and in a less extent Arg) zinc oxide can be found instead.

Sterical factors on the other hand seem to play a role of significantly less importance. The spatial filling of the organic additives becomes relevant, when these molecules are intercalated in LBZs. Then conformation, IEP, charge density and chemical groups determine the amount of co-intercalation of hydroxyl ions as well as the interlayer distance of the LBZs. These statements are still valid when considering dipeptides.

The increase of material deposited on the polyelectrolyte multilayer coating is the most significant consequence of the substrate modification. This can be explained by a higher number of nucleation points on the organic matrix and stronger interactions with the $\mathrm{Zn}$ (II) precursors compared to oxidized silicon surface. Indeed the growth of basic zinc acetate was shown to happen from specific nucleation points at the substrate surface. ${ }^{35)}$ However, the polyelectrolyte multilayer does not control the structure and morphology of the deposit.

Layered basic zinc salts are not thermally stable and are known to transform into zinc oxide structure over $423 \mathrm{~K}^{35)}$ An additional annealing treatment was performed on coatings obtained in the presence of Gly-Glu. Samples were therefore heated at $723 \mathrm{~K}$ for $4 \mathrm{~h}$ in air. Bright field (BF) images (Fig. 7

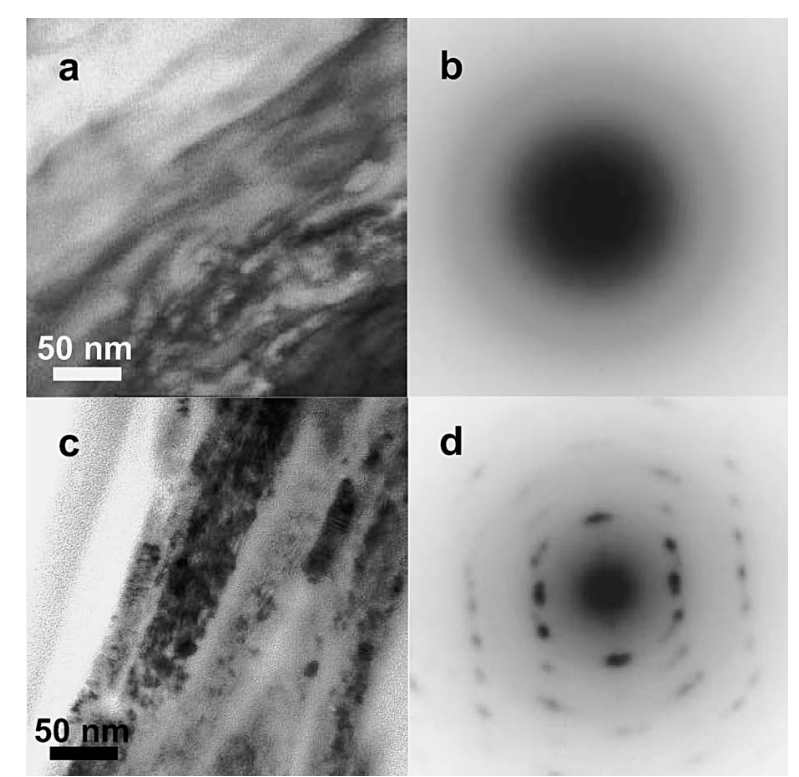

Fig. 7. TEM bright field images and diffraction patterns of deposits on polyelectrolyte multilayers, obtained from solutions of $15 \mathrm{mM}$ $[\mathrm{Zn}], 15 \mathrm{mM}$ HMTA and $1.88 \mathrm{mM}$ Gly-Glu before (a and b) and after (c and d) annealing at $723 \mathrm{~K}$ for $4 \mathrm{~h}$.

(a) and 7 (c)) acquired with the TEM show the cross section of the coated substrate before and after, respectively, the annealing treatment. The $\mathrm{BF}$ micrograph $7 \mathrm{a}$ displays no observable diffraction patterns while in micrograph $7 \mathrm{c}$ the nano-size of the $\mathrm{ZnO}$ crystals can be observed. The corresponding selected area diffraction (SAD) pattern (Fig. 7b and $7 \mathrm{~d}$ ) confirm these observations. The DP of the nonannealed sample (Fig. 7b) is characteristic of an amorphous or low crystalline material. On the contrary, DP acquired from dark zone of the annealed sample, is formed by the superimposition of the diffracted signals originated from each $\mathrm{ZnO}$ nano-crystal (Fig. 7d). It appears that the $\mathrm{ZnO}$ crystals have a strong orientation relation; in fact all the grains illuminated by the electron beam are in the $\langle 010\rangle$ zone axis. The broadening of the signal of the reflections shows that the $\{001\}$ planes of the $\mathrm{ZnO}$ nano-crystals, which are parallel to the substrate, have a mis-orientation between the different grains of approx. $\pm 10^{\circ}$. Consequently, LBZs ribbons formed and staked on the substrate in the presence of Gly-Glu are transformed into $\mathrm{ZnO}$ nano-crystals with a defined orientation and the general morphology of the coating is maintained.

\section{Conclusions}

The thermohydrolysis of aqueous zinc salt solutions for the formation of zinc oxide coatings is strongly modified by the addition of amino acids and peptides. A wide range of morphologies and two different structures were obtained for the inorganic deposit. Week interactions between the biomolecules and zinc compounds yield the classically micrometric $\mathrm{ZnO}$ crystals while stronger interactions in solution or at the crystal seeds interface lead to the formation of $\mathrm{ZnO}$-containing thin films. Layered basic zinc salt formation is favoured in the presence of biomolecules that can be intercalated as anions in that structure. The high variability of the morphologies obtained for the basic salts indicates the chelation of the biomolecules to the zinc ions in solution. These morphologies are preserved during the heat treatment that allows the formation of oriented $\mathrm{ZnO}$ nano-crystals. 
Acknowledgments This project was supported by the KSB foundation and the AvH foundation. The help of Dr. P. Lamparter and Mr. H. Labitzke with XRD and SEM measurements, respectively, is gratefully acknowledged.

\section{References}

1) Horn, D. and Rieger, J., Angew. Chem. Int. Ed., Vol. 40, pp. 4330-4361 (2001).

2) Gao, Y. and Koumoto, K., Cryst. Growth Des., Vol. 5, pp. 1983-2017 (2005).

3) Bill, J., Hoffmann, R. C., Fuchs, T. M. and Aldinger, F., Z. Metallkd., Vol. 93, pp. 478-489 (2002).

4) Niesen, T. P. and Guire, M. R. D., J. Electroceram., Vol. 6, pp. 169-207 (2001)

5) Sohnel, O. and Garside, J., "Precipitation. Basic principles andindustrial applications," Ed. by Söhnel, O., ButterworthHeinemann Ltd., Oxford (1992) pp. 1-391.

6) Colfen, H. and Mann, S., Angew. Chem. Int. Ed., Vol. 42, pp. 2350-2365 (2003).

7) Firouzi, A., Kumar, D., Bull, L., Besier, T., Sieger, P., Huo, Q., Walker, S., Zasadzinski, J., Glinka, C., Nicol, J., Margolese, D., Stucky, G. D. and Chmelka, B. F., Science, Vol. 267, pp. 1138-1143 (1995).

8) Cha, J. N., Stucky, G. D., Morse, D. E. and Deming, T. J., Nature, Vol. 403, pp. 289-292 (2000).

9) Coradin, T. and Livage, J., Colloids Surf., B, Vol. 21, pp. 329-336 (2001).

10) Coradin, T. and Lopez, P. J., ChemBioChem, Vol. 4, pp. 251-259 (2003).

11) Weiner, S. and Dove, P. M., Rev. Mineral. Geochem., Vol. 54, pp. 1-29 (2003).

12) Boskey, A. L., J. Cell. Biochem. Suppls, Vol. 72, pp. 83-91 (1998).

13) Dauphin, Y., Curr. Opin. Colloid Interface Sci., Vol. 7, pp. 133-138 (2002).

14) Kim, I. W., Morse, D. E. and Evans, J. S., Langmuir, Vol. 20, pp. 11664-11673 (2004).

15) Blank, S., Arnoldi, M., Khoshnavaz, S., Treccani, L., Kuntz, M., Mann, K., Grathwohl, G. and Fritz, M., J. Microsc., Vol. 212, pp. 280-291 (2003).

16) Collino, S., Kim, I. W. and Evans, J. S., J. Cryst. Growth, Vol. 6, pp. 839-842 (2006).

17) Gerstel, P., Hoffmann, R. C., Lipowsky, P., Jeurgens, L. P. H., Bill, J. and Aldinger, F., Chem. Mater., Vol. 18, pp. 179-186 (2006).
18) Durupthy, O., Steunou, N., Coradin, T. and Livage, J., J. Phys. Chem. Solids, Vol. 67, pp. 944-949 (2006).

19) Hoffmann, R. C., Jia, S., Bill, J. and Aldinger, F., J. Ceram. Soc. Japan, Suppl., Vol. 112, pp. S1089-S1092 (2004).

20) Hoffmann, R. C., Jia, S., Jeurgens, L. P. H., Bill, J. and Aldinger, F., Mater. Sci. Eng., C, Vol. 26, pp. 41-45 (2006).

21) Decher, G., Science, Vol. 277, pp. 1232-1237 (1997).

22) Strecker, A., Salzberger, U. and Mayer, U., J. Prakt. Metallogr., Vol. 30, pp. 482-482 (1993).

23) Allmann, R., Z. Kristallogr., Vol. 126, pp. 417-418 (1968).

24) Stahlin, W. and Oswald, H. R., Acta Crystallogr., B, Vol. 26, pp. 860-863 (1970).

25) Ghose, S., Acta Crystallogr., Vol. 17, pp. 1051-1057 (1964).

26) Poul, L., Jouini, N. and Fiévet, F., Chem. Mater., Vol. 12, pp. 3123-3132 (2000).

27) Zhang, J., Zhang, F., Ren, L., Evans, D. G. and Duan, X., Mater. Chem. Phys., Vol. 85, pp. 207-214 (2004).

28) Yang, D. and Frindt, R. F., J. Mater. Res., Vol. 11, pp. 1733-1738 (1996).

29) Aisawa, S., Takahashi, S., Ogasawara, W., Umetsu, Y. and Narita, E., J. Solid State Chem., Vol. 162, pp. 52-62 (2001).

30) Hibino, T., Chem. Mater., Vol. 16, pp. 5482-5488 (2004).

31) Nakayama, H., Wada, N. and Tsuhako, M., Int. J. Pharm., Vol. 269, pp. 469-478 (2004).

32) Fudala, Á., Pálinkó, I. and Kiricsi, I., Inorg. Chem., Vol. 38, pp. 4653-4658 (1999).

33) Whilton, N. T., Vickers, P. J. and Mann, S., J. Mater. Chem., Vol. 7, pp. 1623-1629 (1997).

34) Yuan, Q., Wei, M., Evans, D. G. and Duan, X., J. Phys. Chem. B, Vol. 108, pp. 12381-12387 (2004).

35) Hosono, E., Fujihara, S., Kimura, T. and Imai, H., J. Colloid Interface Sci., Vol. 272, pp. 391-398 (2004).

36) Hibino, T. and Tsunashima, A., Chem. Mater., Vol. 9, pp. 2082-2089 (1997).

37) Morioka, H., Tagaya, H., Kadokawa, J.-I. and Chiba, K., J. Mater. Sci. Lett., Vol. 18, pp. 995-998 (1999).

38) Mylonas, M., Krezel, A., Plakatouras, J. C., Hadjiliadis, N. and Bal, W., Bioinorganic Chemistry and Applications, Vol. 2, pp. 125-140 (2004).

39) Rombach, M., Gelinsky, M. and Vahrenkamp, H., Inorg. Chim. Acta, Vol. 334, pp. 25-33 (2002).

40) Reddy, P. R., Mohan, S. K. and Rao, K. S., Chemistry \& Biodiversity, Vol. 2, pp. 672-683 (2005).

41) Vogler, R. and Vahrenkamp, H., Eur. J. Inorg. Chem., Vol. 2002, pp. 761-766 (2002). 